\title{
Relacionamentos Afetivo-Familiares em Mulheres com Anorexia e Bulimia ${ }^{1}$
}

\author{
Carolina Leonidas ${ }^{2}$ \\ Manoel Antônio dos Santos \\ Faculdade de Filosofia, Ciências e Letras de Ribeirão Preto \\ Universidade de São Paulo
}

\begin{abstract}
RESUMO - Este estudo teve por objetivo investigar a rede social de apoio de mulheres com anorexia e bulimia, com ênfase em suas relações afetivo-familiares. A amostra foi composta por 12 participantes atendidas em hospital universitário. Os instrumentos utilizados foram: roteiro de entrevista semiestruturada, Mapa de Rede e Genograma. Os resultados indicaram que as redes sociais das participantes têm configuração restrita, com proeminência de membros da família em sua composição. Os relacionamentos familiares oscilam, contudo, entre turbulência e distanciamento afetivo. As relações de afeto mantidas com pais, cônjuges e namorados são marcadas por divergências e insatisfações. A baixa densidade da rede de amizades e o empobrecimento da vida social resultam em isolamento e dificuldades de dar início e/ou manter relacionamentos afetivos duradouros.
\end{abstract}

Palavras-chave: transtornos alimentares, relações afetivas, família, redes sociais, interação interpessoal

\section{Affective and Family Relationships of Women with Anorexia and Bulimia}

\begin{abstract}
This study aimed to investigate the social support network of women with eating disorders, emphasizing their affective family relations. The sample consisted of 12 participants assisted at a university hospital. The instruments used were a semi-structured interview, Network's Map and Genogram. The results indicated that participant's social networks are restricted, with prominence of family members in their composition. Family relations, however oscillate between affective turbulence and detachment. The affective relationships held with parents, husbands and boyfriends are marked by disagreements and dissatisfactions. The low density of the network of friends and the impoverishment of social life result in isolation and difficulties in initiating and/or maintaining lasting affective relationships.
\end{abstract}

Keywords: eating disorders, affective relationships, family, social networks, interpersonal interaction

Transtornos alimentares (TAs) constituem uma categoria psicopatológica que têm alcançado visibilidade crescente nos últimos anos, em virtude da maior exposição pela mídia de pessoas acometidas, sobretudo modelos, artistas, bailarinos e atletas. Os TAs configuram um contínuo formado por graves perturbações no comportamento alimentar que afetam sobretudo as mulheres jovens. Esses transtornos são 10 vezes mais comuns em mulheres do que em homens e são mais prevalentes em adolescentes e adultos jovens, distribuindose em todos os grupos étnicos (Andrade, Viana, \& Silveira, 2006). Os TAs podem desencadear consequências crônicas e irreversíveis, que se traduzem em comprometimentos nas esferas biológica, psicológica e sócio-interacional (Associação Americana de Psiquiatria, 2002). Os TAs se subdividem basicamente em dois tipos: Anorexia Nervosa (AN) e Bulimia Nervosa (BN) (Ramos \& Pedrão, 2012). Este estudo teve por objetivo investigar a rede de apoio social de mulheres com anorexia e bulimia, com ênfase em suas relações afetivo-familiares.

1 Apoio: FAPESP e CNPq

2 Endereço para correspondência: Faculdade de Filosofia, Ciências e Letras de Ribeirão Preto, Universidade de São Paulo, Avenida Bandeirantes, 3900, Bairro Monte Alegre, Ribeirão Preto, SP, Brasil. CEP: 14.040-901.E-mail: cleonidas@usp.br

\section{Anorexia nervosa}

De acordo com o DSM-IV-TR ${ }^{\mathrm{TM}}$ (Associação Americana de Psiquiatria, 2002), a AN pode ser caracterizada como uma recusa do indivíduo a manter o peso corporal na faixa normal mínima adequada à sua idade e altura, além de um temor intenso de ganhar peso e uma perturbação significativa na percepção da forma ou tamanho do corpo. Esse processo resulta em caquexia, ou seja, em uma fraqueza geral do corpo e má disposição corporal decorrente de graus extremos de desnutrição (Claudino \& Borges, 2002; Morgan, Vecchiatti, \& Negrão, 2002). Existem, ainda segundo o DSM-IV-TR ${ }^{\mathrm{TM}}$, dois subtipos de AN: o restritivo, no qual a paciente perde muito peso em um curto espaço de tempo, devido a dietas, jejuns ou excesso de exercícios físicos, e o purgativo, que se caracteriza por períodos de restrição alimentar intensa, alternados com períodos de compulsão alimentar seguida de rituais purgativos, tais como vômitos autoinduzidos ou uso abusivo de laxantes, diuréticos e drogas anorexígenas.

A dinâmica de personalidade da pessoa com AN é marcada pelo uso de mecanismos de defesa do tipo obsessivocompulsivo (meticulosidade, perfeccionismo, ruminação mental), na tentativa de se proteger de sentimentos de inferioridade, inadequação e insegurança, com predomínio de emoções negativas, retraimento social e condutas de evitação (Borges, Sicchieri, Ribeiro, Marchini, \& Santos, 2006; Campana, Tavares, \& Garcia Júnior, 2012; Cassin \& Von Ranson, 2005; Nilsson, Sundbom, \& Häglöff, 2008; Peres \& Santos, 2006). Cooper, Deepak, Grocutt e Bailey (2007) 
sugerem que a experiência de "sentir-se gorda", vivenciada intensamente pelas pacientes com TAs, está relacionada a uma combinação de fatores. Os autores destacam entre esses fatores a presença de sensações corporais internas e externas associadas à distorção da imagem corporal, que resultam em sentimentos de angústia, rejeição e exclusão social, que acentuam crenças negativas sobre si mesmas.

Morgan et al. (2002) apontam que a etiologia dos TAs é multifatorial, ou seja, vários fatores interagem entre si de uma forma complexa e se conjugam na produção dos sintomas. Entre os principais fatores figuram: vulnerabilidade genética, traços de personalidade, psicopatologia parental, experiências adversas, pressões socioculturais, entre outros. Oliveira e Santos (2006) propõem a hipótese de uma influência combinada da dinâmica familiar - confusão das fronteiras que definem os subsistemas familiares, o que dificultaria a formação da própria identidade e individualidade nos membros da família, com elementos do meio cultural em interação com aspectos individuais da personalidade. Esses fatores são concorrentes na determinação da etiopatogenia dos distúrbios relacionados à distorção da imagem corporal, que predispõem ao desenvolvimento dos TAs.

\section{Bulimia Nervosa}

Bulimia significa, do ponto de vista etimológico, "fome de boi". O termo remete a um apetite ávido, ao qual o indivíduo se entrega com avidez e voracidade. Esse apetite, no entanto, não diz respeito apenas aos alimentos em si, mas a uma gama de objetos e atividades. Contrapondo-se à preocupação com a economia e o estabelecimento de medidas rígidas de controle sobre o apetite - tendências típicas da cultura contemporânea -, a bulimia "aparece como o espelho invertido do culto do rendimento" da sociedade contemporânea (Brusset, 2003, p. 8) e, como tal, ilustra os efeitos do consumo desmedido que preside a lógica da sociedade de mercado.

$\mathrm{O}$ exagero típico dos quadros de $\mathrm{BN}$ geralmente ocorre em forma de atos privados e solitários. Configura um ataque à cozinha, à educação e aos costumes aprendidos, subvertendo as necessidades biológicas da fome e contestando o que é aceito ética e esteticamente, assim como as normas, os usos, os aprendizados e a dimensão social da refeição (Brusset, 2003). Após os ataques impulsivos desferidos, surgem as autorreprovações morais e um intenso sentimento de vergonha vivenciado pelas pessoas acometidas por esses quadros (Rosa \& Santos, 2011).

Segundo o DSM-IV-TR ${ }^{\mathrm{TM}}$ (Associação Americana de Psiquiatria, 2002), constituem critérios diagnósticos para a BN: 1) Episódios recorrentes de compulsão alimentar periódica, que são caracterizados por: 1.1) ingestão, em período limitado de tempo, de uma quantidade de alimentos definitivamente maior do que a maioria das pessoas consumiria em período e circunstâncias similares; 1.2) sentimento de falta de controle sobre o comportamento alimentar durante o episódio (por exemplo, sentimento de incapacidade de parar de comer ou de estimar o quanto está comendo); 2) Comportamento compensatório inadequado e recorrente, com a finalidade de prevenir o aumento de peso, como autoindução de vômitos, uso indevido de laxantes, diuréticos, enemas ou outros medicamentos, jejuns ou exercícios excessivos; 3) A compulsão alimentar periódica e os comportamentos compensatórios inadequados ocorrem, em média, pelo menos duas vezes por semana, por um período de três meses; 4) A autoavaliação do indivíduo é indevidamente influenciada pela forma e pelo peso corporal; 5) O distúrbio não ocorre exclusivamente durante os episódios de AN.

Estudo de base populacional realizado em um município do Nordeste, que investigou a relação entre os transtornos alimentares e o trabalho, encontrou prevalência de $\mathrm{BN}$ equivalente a $1,0 \%$. As prevalências foram mais elevadas entre os indivíduos que apresentaram insatisfação com o peso, consumo abusivo de álcool, história de agressão na infância, dificuldades financeiras, que tinham vínculo informal de trabalho e que estavam no grupo de trabalho de alta exigência (Prisco, Araújo, Almeida, \& Santos, 2013).

Do ponto de vista do funcionamento psicológico, as pacientes com BN apresentam uma série de pensamentos e emoções desadaptativas a respeito de seus hábitos alimentares e seu peso corporal (Abreu \& Filho, 2004). Além disso, também apresentam autoestima flutuante e acreditam que o corpo bem delineado resolveria seus problemas de insegurança pessoal. No afã de alcançar o corpo idealizado, as mulheres com BN se engajam em dietas excessivas, alternadas com episódios de compulsão alimentar, que são seguidos de rituais purgativos e compensatórios. Assim, atribui-se o desejo que essas mulheres apresentam de emagrecer a uma desorganização pessoal, na qual a regulação e o controle da alimentação seriam uma tentativa de obter ordenação e estabilidade do seu estado psíquico caótico (Abreu \& Filho, 2004; Rosa \& Santos, 2011).

\section{Transtornos alimentares e rede social de apoio}

A literatura específica acerca dos TAs engloba uma quantidade significativa de estudos que apontam para a rede social familiar como a principal fonte de apoio à pessoa acometida (Dimitropoulos, Carter, Schachter, \& Woodside, 2008; Kluck, 2008; Leonidas \& Santos, 2012; Leonidas, Crepaldi, \& Santos, 2013; Limbert, 2010; Marcos \& Cantero, 2009; Souza \& Santos, 2009, 2010). Marcos e Cantero (2009) destacam que, dentre os membros da família, a mãe e o cônjuge são considerados as principais fontes de apoio social de mulheres com TAs, e essas mulheres admitem estar satisfeitas com o apoio recebido da rede familiar. Outros estudos, como o de Limbert (2010), apontam, porém, para uma relação entre insatisfação com o apoio social recebido da rede familiar e os sintomas de TAs. Desse modo, os estudos realizados não são conclusivos, o que justifica a necessidade de novas investigações.

Estudo de Leonidas et al. (2013) evidenciou que há relação entre aspectos da personalidade da paciente com BN e o empobrecimento da rede de apoio social, o que incrementa sentimentos de tristeza, solidão e isolamento social. O comprometimento do potencial de apoio da rede, por sua vez, acaba por intensificar as vivências de desamparo e menos-valia. 
Bryant-Waugh e Lask (1995) argumentam que a desarmonia familiar, a separação do casal e a falta de consistência na resposta dos pais ao transtorno do(a) filho(a) podem ser considerados fatores mantenedores do quadro psicopatológico. Outros autores (Lane, 2002; Soenens et al., 2008) acrescentam ainda que indivíduos com TAs provêm de lares com mães controladoras, perfeccionistas e pais ausentes, além de estarem frequentemente expostos a histórias de traumas que permeiam os enredos familiares.

Dallos e Denford (2008) sugerem que os relacionamentos nas famílias com um membro acometido por TA se processam sobre uma base falsa ou frágil, com predomínio de vínculos problemáticos, conflitos, discussões frequentes, triangulação, desconforto e relação negativa com a alimentação. Os autores pontuam que as experiências de relacionamentos conflituosos, bem como padrões de comunicação confusos, são comuns entre os membros familiares, e destacam a presença de triangulações.

A triangulação concerne a conjuntos de relações estabelecidas entre três pessoas, nas quais o funcionamento de uma depende e influencia o comportamento das outras duas. A configuração das triangulações nas famílias envolve duas pessoas unidas e aliançadas em relação a uma terceira, e tem o objetivo de reduzir a tensão existente entre a dupla (Dallos \& Denford, 2008). Nos TAs, as relações familiares apresentam padrões típicos de ansiedade, ambivalência e preocupação excessiva, principalmente na relação entre mãe e filha, o que costuma implicar na exclusão de um terceiro - no caso, o pai -, caracterizando assim a triangulação.

Dallos e Denford (2008) sugerem que mulheres acometidas por esses quadros vivenciam sensações frequentes de conflitos reais ou iminentes entre os pais, além de se sentirem aprisionadas no centro desses conflitos, sendo frequentemente coagidas a tomar partido de um dos genitores. Considerando esses pressupostos, pode-se hipotetizar que a relação de superenvolvimento entre mãe e filha seja reflexo, dentre outros fatores, de tensões implícitas na relação do casal, que muitas vezes se encontram encobertas pelo TA da filha.

Pode-se considerar, portanto, que o quadro psicopatológico funcionaria como uma maneira de os pais desviarem sua atenção e se "distraírem" de seus próprios conflitos (McGoldrick, Gerson, \& Petry, 2008). Vale ressaltar que os conflitos conjugais do casal parental configuram apenas um dentre os diversos aspectos psicológicos que contribuem para perpetuar o superenvolvimento que caracteriza a relação entre mãe e fillha. Outras problemáticas podem atuar como potenciais contribuidores, como os conflitos geradores de sofrimento psíquico que, não podendo ser elaborados, articulam-se em conteúdos inconscientes que são transmitidos transgeracionalmente na relação estabelecida entre mãe e filha acometida (Valdanha, Scorsolini-Comin, \& Santos, 2013).

Oliveira e Hutz (2008) encontraram diferenças no funcionamento de famílias com adolescentes acometidos por anorexia nervosa restritiva e purgativa. Os padrões de interação identificados no primeiro quadro evidenciam regras rígidas e disfuncionais, dificuldade na expressão de conflitos e submissão materna. No segundo quadro observouse dificuldade marcada de individualização, manifestação destrutiva da agressividade e falta de sintonia comunicacional entre os membros.

Além do funcionamento familiar em si, a literatura aponta que eventos estressores ocorridos dentro do ambiente familiar também podem estar relacionados com comportamentos alimentares disfuncionais e formas não saudáveis de controle de peso, que surgiriam como modos de lidar com os afetos disruptivos e estados psíquicos intoleráveis, ou como tentativas de reduzir a tensão suscitada pelas emoções negativas (Berge, Loth, Hanson, Croll-Lampert, \& NeumarkSztainer, 2012).

Como fontes de distress mais relevantes são mencionadas: divórcio dos pais, morte de um membro da família, mudança de escola, casa ou trabalho dos pais, incidência de doença grave (ou hospitalização) em um membro familiar, violência ou abuso sexual e incesto. A ocorrência de eventos transicionais no ciclo de vida de toda família não costuma ser acompanhada do apoio social necessário para que os membros possam elaborá-los e superá-los. Assim, a ausência de apoio social intensificaria as dificuldades emocionais vivenciadas, o que pode servir de gatilho para a precipitação do TA.

Apesar de a família emergir cada vez mais na literatura especializada como possível fonte de distress e, paradoxalmente, como fonte mais significativa de apoio social para as pessoas com TAs, nota-se uma lacuna do conhecimento produzido em relação ao apoio recebido de outras redes sociais, tais como amigos, cônjuges, colegas de trabalho e de estudo, organizações religiosas, instituições de saúde, entre outros recursos comunitários. Nesse panorama, destaca-se a necessidade de investigações que forneçam esclarecimentos mais pormenorizados a respeito das redes sociais de apoio no contexto dos TAs, já que as evidências sugerem que, quanto melhor a percepção que as pessoas tiverem da rede na qual estão inseridas e do apoio social recebido por meio desta, melhor será o prognóstico.

Acresce-se a isso o fato de que os TAs configuram uma condição crônica estigmatizante e ainda obscura para a maior parcela da população, que ignora as características essenciais do diagnóstico, tratamento e prognóstico. Esse desconhecimento alimenta a incompreensão por parte de familiares, professores e colegas de trabalho, incrementando o isolamento social e o sentimento de desamparo e menosvalia da pessoa acometida (Scorsolini-Comin, Souza, \& Santos, 2010). Em decorrência disso, o profissional de saúde deve investigar de modo pormenorizado as dimensões constitutivas da rede social de apoio das pacientes, de modo a assegurar o adequado estabelecimento do plano terapêutico individual (Filho \& Nóbrega, 2004; Leonidas, \& Santos, 2012; Resende, Bones, Souza, \& Guimarães, 2006).

Diante do exposto, pode-se postular que as mulheres com TAs apresentam dificuldades no estabelecimento e manutenção de relacionamentos interpessoais e afetivos, uma vez que sua dinâmica psíquica engloba emoções e pensamentos disfuncionais que as impedem de compartilhar sua vida com o outro de maneira genuína e satisfatória. Nesse sentido, acredita-se que as possíveis dificuldades encontradas no plano das interações sociais e afetivas podem estar relacionadas à predisposição, perpetuação e/ou manutenção do quadro psicopatológico do TA. 
Poucos estudos têm se dedicado a investigar essas questões, o que demanda a realização de novas pesquisas. $\mathrm{O}$ presente estudo teve como objetivo investigar a rede social de apoio de mulheres com TAs, com ênfase em suas relações afetivo-familiares, tendo como eixo as relações de afeto mantidas com os pais, cônjuges/namorados e amigos.

\section{Método}

Adotou-se um delineamento descritivo-exploratório, no enfoque de pesquisa qualitativa. $\mathrm{O}$ estudo consiste em um recorte da dissertação de mestrado intitulada Redes Sociais e Apoio Social no Contexto dos Transtornos Alimentares (Leonidas, 2012). Nesse recorte foram privilegiados os resultados relativos às relações afetivo-familiares.

\section{Participantes}

A amostra foi constituída por 12 mulheres que se encontravam em seguimento regular durante o período de coleta de dados (de abril a dezembro de 2010) em um serviço de assistência multiprofissional em TAs de um hospital universitário da região sudeste do Brasil. Ressalta-se que a inclusão de participantes apenas do sexo feminino se deve à elevada prevalência de mulheres dentre os pacientes acometidos por TAs (Prisco et al., 2013). Estudo realizado por Andrade et al. (2006) mostrou que a incidência média anual de TAs em mulheres é de 18,5 por 100.000 , enquanto que em homens é da ordem de 2,25.

Foram incluídos todos os pacientes que, consecutivamente, compareceram ao serviço e atenderam aos critérios de inclusão: ser do sexo feminino, ter idade igual ou superior a 18 anos e ter diagnóstico confirmado de TA, independentemente do subtipo específico, faixa etária, grau de escolaridade, estado marital, tempo de acometimento e comorbidade psiquiátrica.

Foram excluídos pacientes com condições clínicas agravadas e/ou acentuada dificuldade de compreensão e comunicação. A idade média das participantes corresponde a 27,7 anos, com idade mínima de 20 e máxima de 40 anos. Oito delas tinham diagnóstico de $\mathrm{AN}$ do tipo purgativo e quatro receberam diagnóstico de BN. Esses dados, assim como as variáveis antropométricas obtidas a partir de consultas aos prontuários hospitalares, podem ser melhor observados na Tabela 1. Para resguardar o anonimato e preservar a confidencialidade dos dados, os nomes das participantes foram substituídos por nomes fictícios, escolhidos por elas próprias ao final da entrevista.

\section{Instrumentos}

Foram utilizados os seguintes instrumentos para a coleta de dados:

a) Roteiro de entrevista semiestruturada: subdividido em duas partes, a primeira dedicada à coleta de dados sociodemográficos e a segunda constituída pelos seguintes temas: informações acerca do TA: início e evolução dos sintomas; situação emocional da participante; a rede social e pessoal (questões voltadas à construção do Mapa de Rede) e a rede familiar da participante (questões para elaboração do Genograma).

b) Mapa de Rede: proposto por Sluzki (1997), trata-se de uma representação gráfica da rede social do indivíduo, na qual seus componentes são distribuídos em um "mapa" constituído de um círculo dividido em quatro quadrantes, relacionados à família, amizades, relações de trabalho ou estudo, relações comunitárias e com instituições (no caso do presente estudo, o serviço clínico de assistência em TAs).

Tabela 1. Caracterização das participantes segundo o diagnóstico, peso, altura, IMC na admissão e no momento de participação neste estudo, e tempo de tratamento no serviço

\begin{tabular}{|c|c|c|c|c|c|c|c|}
\hline Participantes & $\begin{array}{l}\text { Idade } \\
\text { (anos) }\end{array}$ & Diagnóstico & Peso (kg) & Altura (m) & $\begin{array}{c}\text { IMC de } \\
\text { admissão } \\
\left(\mathbf{k g} / \mathbf{m}^{2}\right)\end{array}$ & $\begin{array}{c}\text { IMC atual } \\
\left(\mathrm{kg} / \mathrm{m}^{2}\right)\end{array}$ & $\begin{array}{c}\text { Tempo de } \\
\text { tratamento } \\
\text { no serviço } \\
\text { (meses) }\end{array}$ \\
\hline Maria & 30 & AN do tipo purgativo & 49,1 & 1,64 & 17,8 & 18,3 & 22 \\
\hline Grazieli & 20 & $\mathrm{BN}$ & 59,3 & 1,65 & 23,5 & 21,9 & 10 \\
\hline Sissi & 27 & $\mathrm{BN}$ & 63,4 & 1,75 & 21,2 & 20,6 & 12 \\
\hline Sofia & 27 & AN do tipo purgativo & 44,1 & 1,72 & 14,7 & 14,9 & 6 \\
\hline Bárbara & 24 & AN do tipo purgativo & 56,4 & 1,60 & 21,9 & 21,9 & 1 \\
\hline Carolina & 31 & $\mathrm{BN}$ & 101,3 & 1,65 & 36,1 & 37,2 & 84 \\
\hline Fernanda & 40 & AN do tipo purgativo & 70,8 & 1,74 & 16,7 & 23,2 & 184 \\
\hline Amanda & 22 & AN do tipo purgativo & 50,8 & 1,66 & 17,3 & 18,4 & 48 \\
\hline Juliana & 30 & AN do tipo purgativo & 53,3 & 1,67 & 20,4 & 19,1 & 168 \\
\hline Marina & 29 & $\mathrm{BN}$ & 60,7 & 1,69 & 20,0 & 21,5 & 60 \\
\hline Estrelinha & 28 & AN do tipo purgativo & 47 & 1,71 & 15,9 & 15,9 & 1 \\
\hline Ana & 24 & AN do tipo purgativo & 40,6 & 1,52 & 15,7 & 17,5 & 60 \\
\hline
\end{tabular}


c) Genograma: trata-se de uma estrutura de gráficos padronizada, utilizada para representar a formação interna de uma família (Wright \& Leahy, 2002). Tem por objetivo levantar informações sobre os membros e as relações familiares no decorrer das gerações, permitindo detectar padrões de vínculos e tipos de fronteiras estabelecidas naquele contexto (McGoldrick et al., 2008).

\section{Procedimentos}

\section{Coleta de dados}

Foi obtida aprovação do Comitê de Ética em Pesquisa da instituição hospitalar, processo $\mathrm{n}^{\circ} 2155 / 2010$. As participantes assinaram o Termo de Consentimento Livre e Esclarecido. A aplicação dos instrumentos foi realizada individualmente, em encontro único e local reservado do serviço especializado em TAs. Os nomes mencionados pelas participantes foram anotados, assim como foi identificado o tipo de relação existente entre as participantes e os membros da rede, o que possibilitou examinar detalhadamente a proximidade e o tipo de vínculo estabelecido com cada indivíduo. O Mapa de Rede e o Genograma foram recursos complementares à entrevista semiestruturada.

\section{Análise dos dados}

As entrevistas audiogravadas foram transcritas na íntegra e literalmente, e o material coligido foi submetido à análise de conteúdo na modalidade temática (Bogdan \& Biklen, 1994). Os Mapas de Rede e os Genogramas foram elaborados manualmente pela pesquisadora durante a coleta de dados. Posteriormente, foram diagramados com o uso de programa específico para criação de elementos gráficos (CorelDRAW Graphics Suite).

A interpretação dos resultados obtidos com a aplicação desses instrumentos baseou-se nas pautas de análise preconizadas pela literatura (McGoldrick et al., 2008; Moré, 2005; Orlandi, 2011; Wendt \& Crepaldi, 2008). Os dados extraídos da análise dos instrumentos foram organizados em categorias temáticas, levando-se em conta os núcleos de sentido - ou seja, a regularidade das respostas e os padrões convergentes de conteúdo, obtidos tanto nos relatos, quanto nas ilustrações gráficas extraídas dos Mapas de Rede e Genogramas.

\section{Resultados e Discussão}

Os núcleos de sentido encontrados foram aglutinados em torno de cinco categorias temáticas, que serão apresentadas e discutidas a seguir.

\section{Família como a rede social mais significativa}

A análise gráfica dos Mapas de Rede evidenciou que a família configurava a rede social mais significativa das participantes, uma vez que o quadrante da Família englobava o maior número de membros. Além disso, os relatos das participantes nas entrevistas foram convergentes no que concerne ao fato de os membros desempenharem a maior parte das funções de apoio propostas por Sluzki (1997), tais como: companhia social, apoio emocional, guia cognitivo e de conselhos, serviços e cuidados, ajuda material e financeira. Esse dado pode ser melhor visualizado na ilustração gráfica do Mapa de Rede de Ana (Figura 1).

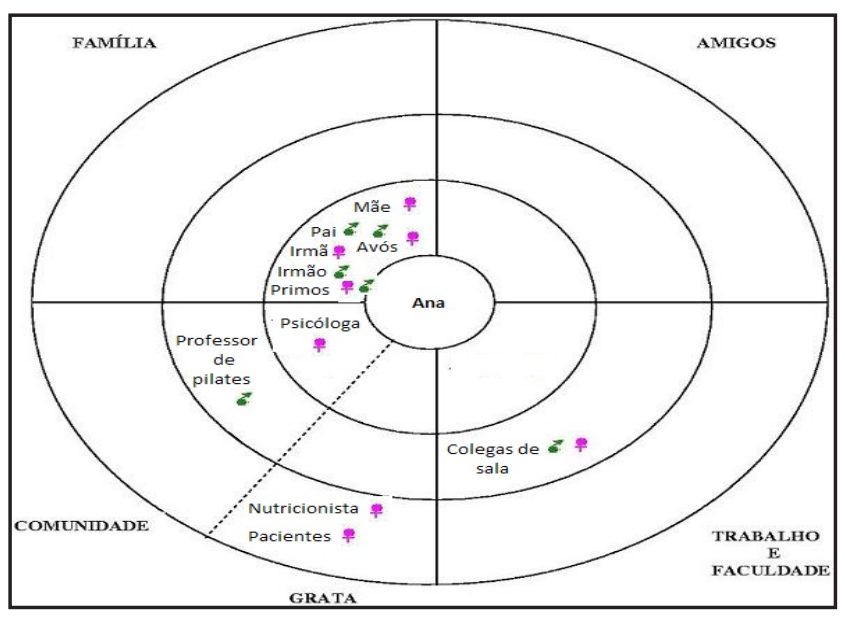

Figura 1. Mapa de Rede da participante Ana

A ambiguidade das relações familiares, com alternância entre padrões de conflitos e de apoio social, ficou bastante marcada nos relatos de seis participantes - Bárbara, Maria, Fernanda, Sissi, Grazieli e Sofia. Durante as entrevistas emergiram, predominantemente, relatos de desavenças e dissensões familiares, assim como de situações traumáticas que marcaram a vida emocional das participantes, tais como: separação dos pais (Amanda), relacionamento extraconjugal do pai (Sofia e Sissi), cobrança excessiva por parte dos pais (Bárbara, Maria e Grazieli), incompreensão por parte dos irmãos (Grazieli, Fernanda), alcoolismo do pai (Sofia), dentre outros fatores desencadeadores de turbulência familiar.

O meu pai sempre foi um pai muito violento, batia na minha mãe... Eu sempre vi, ele sempre foi adúltero e... Eu sempre cresci muito revoltada, eu e minhas irmãs... Ai, quando eles largaram, ele tentou matar minha mãe... E aí, foi nessa época que eu fiquei... que aconteceram muitas coisas. (Sissi)

Notadamente as relações com o pai e os irmãos foram consideradas vulneráveis, marcadas por situações de desentendimentos, rixas, altercações e desavenças não resolvidas, bem como de exposição a eventos traumáticos. Segundo os relatos obtidos, os membros da família (sobretudo pai e irmãos) afirmam peremptoriamente que não compreendem e não aceitam o diagnóstico de TA. Nas participantes do presente estudo, os conflitos com o pai e os irmãos já eram preexistentes ao transtorno, resultando em relações que podem facilmente se tornar conflituosas, notadamente diante da ocorrência de adversidades como um agravamento do quadro psicopatológico. Apenas três participantes (Ana, Amanda e Juliana) mencionaram manter uma relação de aliança com os irmãos, que foram considerados como fontes significativas de apoio social. 
Foram evidenciadas situações de triangulação presentes na dinâmica familiar de sete participantes - Sissi, Grazieli, Maria, Juliana, Estrelinha, Amanda e Ana. Os triângulos eram configurados por relações fusionais e conflituais (ou de aliança) entre mães e filhas, que atuavam em relação a um terceiro: o pai (McGoldrick et al., 2008). Hipotetiza-se que essas triangulações tenham como função primordial ocultar a relação emocionalmente (ou fisicamente, como no caso dos pais de Amanda) distante do casal parental, por meio do direcionamento de atenção e preocupação excessivas em relação à filha acometida. No entanto, apesar dos conflitos descritos nas entrevistas, todas as participantes mencionaram a família como sua principal fonte de apoio, especialmente a figura da mãe - Carolina, Sissi, Fernanda e Grazieli - ou o casal parental - Juliana, Maria, Sofia, Ana e Bárbara.

\section{Dinâmica familiar: entre a turbulência e o distanciamento afetivo}

Os relatos de três participantes - Sofia, Sissi e Grazieli-, revelaram que a dinâmica familiar anterior à ocorrência do TA era marcada por relacionamentos permeados por contendas ("brigas") entre os membros, resultantes de dissensões que, frequentemente, desembocavam em discussões acaloradas e episódios de violência física. Sofia relata que o pai fazia uso abusivo de álcool, a mãe apresentava quadro depressivo e o casal "brigava" constantemente. As "brigas" reiteradas parecem ter resultado no distanciamento emocional entre os membros da família. Instada a situar temporalmente o início desse afastamento, a participante refere que fora "desde sempre".

No caso de Sissi, o pai mantinha relacionamentos extraconjugais, que acabavam se tornando do conhecimento de todos. Além disso, era agressivo e extremamente violento no relacionamento com a esposa. Chegou a ser detido e permaneceu preso por alguns meses por violência física perpetrada contra a mulher. A participante relata que "cresceu com transtorno de paternidade" (sic), pois sempre teve muita raiva e ao mesmo tempo medo do pai, o que aprofundou o distanciamento entre ambos.

Grazieli, por sua vez, não mencionou ter sido exposta à violência física, mas trouxe a vivência recorrente de negligência, abandono e distanciamento afetivo por parte dos pais desde a infância: os pais sempre trabalharam e "não a acompanhavam" no dia a dia. Além disso, a participante também relatou que sempre se sentira sufocada e "cobrada" pelo pai, que não a deixava sair de casa, nem permitia que dormisse na casa das amigas. Grazieli mencionou ainda a relação disfuncional que mantinha com o irmão, com quem "sempre brigou muito", uma vez que sentia que "tudo era pra ele, tinha de ser do jeito dele”.

Os relatos de outras três participantes - Fernanda, Ana e Maria -, apontaram uma dinâmica familiar marcada por distanciamento - com e/ou entre os pais e/ou irmãos. Fernanda relatou que, antes da ocorrência do TA, havia um distanciamento entre os membros de sua família, uma vez que suas irmãs “pensavam muito em si mesmas”. Entretanto, no que concerne à relação estabelecida com a mãe, Fernanda referiu que sempre foram muito próximas.
A participante Maria mencionou que sempre mantivera uma relação distante com o pai, que foi caracterizado como autoritário, uma pessoa com quem era difícil estabelecer uma relação de intimidade. Houve um período, muito anterior à instalação do TA, que Maria esteve afetivamente muito próxima à mãe, mas essa relação foi se "desgastando" com o tempo, de modo a ampliar progressivamente o distanciamento.

Ana, por sua vez, relatou que se ressente da falta de diálogo na família. Contou que mantinha um relacionamento afetivo superficial e distante com o pai, a quem referiu como alguém indiferente aos seus problemas.

\begin{abstract}
Ah, talvez eu gostaria de... Porque eu não sei se tem tempo pra isso, né? Porque é a família que eu conheço... Mas eu... Eu não sei se tem tempo ou se tem alguém que queira, se é o perfil de alguém, mas eu gostaria de discutir mais sobre as outras coisas, sabe? Sobre o mundo, sobre alguns outros assuntos, saber a opinião deles... E dar a minha, sabe? [...] Então, meu pai... eu não converso muito, a gente só conversa assim, coisas do outro... Coisas de outras pessoas, às vezes ele conta de alguém que eu conheço, assim... Mas ele não conversa muito, não tem diálogo. (Ana)
\end{abstract}

No caso de Amanda, o afastamento da figura paterna ocorreu após a separação dos pais. A participante relatou que mantinha um relacionamento bastante próximo com o pai, mas isso se alterou quando ele se separou e deixou o lar para se casar com outra mulher. Durante as internações de Amanda no hospital, em consequência de seu estado de extrema desnutrição, o pai fazia visitas à filha no período da manhã, para evitar de se encontrar com a mãe, que a visitava no período da tarde. No entanto, após poucos dias de internação, o pai encerrou as visitas sem qualquer razão aparente e seus encontros foram se tornando cada vez mais esporádicos desde então. Quando questionada a respeito de como percebia atualmente a relação com o pai, a participante relatou que gostaria que fosse diferente, mas que "não encana com isso", aparentando certa indiferença.

Bárbara foi a única participante que relatou a existência de relacionamentos "mais tranquilos" com e entre os familiares na fase anterior à instalação do quadro psicopatológico. No que concerne às relações familiares, autores como Bryant-Waugh e Lask (1995), Lane (2002) e McNamara e Loveman (1990) pontuam que as famílias de pacientes com TAs geralmente apresentam desarmonia, pouco afeto e respeito mútuo entre seus membros, comunicação empobrecida, escassa habilidade para a resolução de conflitos, mães excessivamente controladoras e pais ausentes ou fragilizados. Os relatos das participantes e os achados extraídos da configuração dos Genogramas e dos Mapas de Rede corroboram esses dados da literatura, uma vez que evidenciaram que as relações familiares são marcadas por conflitos e dissensões crônicas, que acentuam a sensação de incompreensão e ausência de proteção, empatia e vínculos afetivos solidários.

A ausência da figura paterna foi percebida nos casos de Fernanda e Carolina, que não mencionaram o pai durante as entrevistas, exceto quando interrogadas a esse respeito no momento da construção do Genograma. Em relação às par- 
ticipantes Sofia, Sissi, Grazieli, Maria, Juliana e Estrelinha, constatou-se a ocorrência de graves conflitos entre elas e seus pais, que parecem ter culminado em um distanciamento significativo, com notável esgarçamento dos vínculos. Esse dado pode ser ilustrado pelo Genograma de Estrelinha (Figura 2), no qual está representada a relação vulnerável com o pai, que caracteriza um vínculo no qual não há conflito explícito, mas existe a possibilidade da ocorrência de conflitos sob condições adversas ou em fases de transição (Wendt \& Crepaldi, 2008).

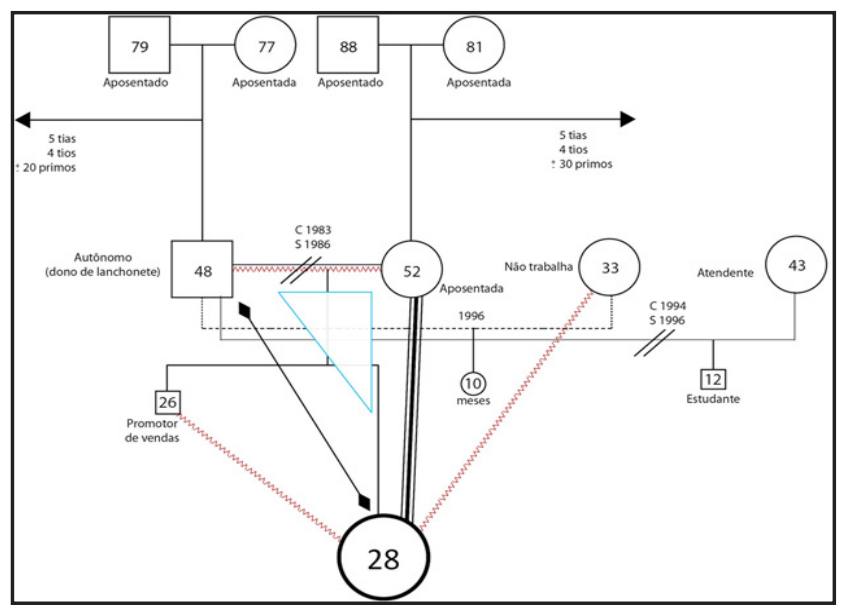

Figura 2. Genograma da participante Estrelinha

Duas participantes - Carolina e Marina - reportaram a existência de conflitos e relacionamento abusivo também na relação com seus próprios filhos. Elas admitiram que foram física e verbalmente violentas com os mesmos, principalmente na época em que os sintomas de TAs encontravam-se mais aguçados. No presente, ambas relataram que mantêm relações que alternam entre épocas mais tumultuosas e outras, em que predominam relações mais afetuosas. O relato de Marina evidenciou uma relação fusional com a filha, na qual se observa ambivalência afetiva, caracterizada por sentimentos intensos de amor e ódio direcionados ao mesmo objeto.

É, eu xingo eles, fico brava com eles, ponho eles pra dentro, se precisar dou uns "tampa-olho" neles, mas não é tão constante mais, né. (Carolina)

Minha filha tem 11 anos, só que, sabe, ela está do meu tamanho, o corpo dela é lindo. Lindo, lindo, lindo. Quando ela está se trocando, está assim de calcinha e sutiã, eu fico assim, babando. Teve época que, assim, eu e ela brigávamos constantemente, até comentei com a psicóloga, ela disse: "Mas não é certo, ela é uma criança, está se desenvolvendo agora”. E ela, pra me provocar, ela ficava me insultando: "Olha o meu corpo, você não tem o meu corpo". (Marina)

\section{Relações afetivas como fatores estressores}

A exposição reiterada a eventos estressores vinculados às relações interpessoais aparece nos discursos de oito participantes do presente estudo - Maria, Bárbara, Grazieli, Sissi, Juliana, Marina, Estrelinha e Fernanda. Morgan et al.
(2002) pontuam que a ocorrência de experiências adversas é um dos aspectos que, ao interagir com outros fatores predisponentes de forma complexa, pode precipitar o quadro de TA. Tais eventos podem englobar: comentários sobre o peso corporal, término de relacionamento, perda de um ente querido, separação dos pais, entre outros.

No caso de Maria, o casamento na adolescência e a separação após um ano de união parecem ter contribuído para o desencadeamento dos sintomas nessa etapa da vida. A participante relatou que seu relacionamento conjugal foi bastante conturbado, pois o ex-marido "não aceitava o jeito dela, a sua personalidade". A participante permaneceu em silêncio quando questionada a respeito de sua adolescência, restringindo suas respostas a generalidades como: "aconteceram muitas coisas, não consigo ligar exatamente a alguma coisa".

No caso de Bárbara, a perda de pessoas próximas - que, segundo a participante, afastaram-se de seu convívio por "estarem seguindo seus próprios caminhos", e não por motivos relacionados a ela -, juntamente com os apelidos depreciativos que recebia da irmã e dos amigos da escola durante a infância e pré-adolescência - era chamada, jocosamente, de Bulufas - parecem ter contribuído para a instalação do transtorno. Além disso, a participante era apaixonada por um rapaz da escola, que começou a namorar uma outra menina, caracterizada por Bárbara como supermagra.

A soma dessas frustrações, que a participante denominou de "perdas" acumuladas, foi associada ao peso e à forma corporal de Bárbara, que iniciou uma busca frenética por emagrecimento como forma de "provar algo" às pessoas: "Eu queria mostrar pros outros que eu podia". Comentários depreciativos a respeito do peso também foram mencionados por Juliana como um dos fatores precipitantes do TA, principalmente pelo fato desses comentários terem sido reiterados pelo próprio pai.

Grazieli reconheceu que o fato de se sentir "cobrada e sufocada" pelo pai desde a infância pode ter gerado sentimentos de angústia e ansiedade, que ela "descontava" na ingesta excessiva de alimentos, buscando depois obter alívio por meio de manobras purgativas, como o vômito autoinduzido. No entanto, notou-se que há uma cobrança autodirigida de Grazieli, ou seja, a própria participante exige muito de si mesma: considera que precisa ser magra para poder se adequar ao balé. Também sente que precisa trabalhar de forma eficiente na banca de revistas dos pais e que não pode gastar dinheiro em função de uma dívida que os pais contraíram. Assim, no caso de Grazieli, a dívida contraída pelos pais parece ter sido o principal evento estressor que favoreceu a instalação do TA, uma vez que a "cobrança" tanto por parte do pai, como de si mesma - foi intensificada a partir desse acontecimento.

Relacionamento extraconjugal do marido, no caso de Marina, e término de um longo namoro, no caso de Estrelinha, também surgiram nas falas das participantes como eventos que precipitaram a ocorrência do TA. Estrelinha confidenciou uma série de conflitos relacionados ao namoro, que culminaram na separação do casal. Essa separação, juntamente com o fato de que o namorado "não dava atenção" a ela, fez com que a participante se sentisse muito triste e 
com baixa autoestima, o que, segundo ela, despertou seu desejo de perder peso. Marina, por sua vez, relatou que, ao saber que havia sido traída pelo marido, considerou que o emagrecimento seria uma forma de fazer com que ele se interessasse por ela novamente.

Eu achei, assim... que eu amava ele demais, eu não queria perder ele, imaginava que, pelo fato de ele ter me traído com a minha prima, e minha prima era assim, bem magrinha... Eu nunca fui gorda, sempre tive esse corpo. Eu pensei assim: "Nossa, ele gosta de mulher bem magra. Então, se eu ficar assim bem magra igual a ela, ele nunca vai largar de mim, não vai me abandonar". Então foi onde eu comecei a comer e vomitar, fazer regime, dai eu comecei a tomar um monte de remédio, tomei um monte de chá, foi assim que tudo começou.

Nota-se que as dificuldades vivenciadas nas relações afetivas e conjugais configuram a maior parte do que as participantes caracterizaram como fatores precipitadores do TA. Tais relações eram bastante conflituosas e, tomando-se como base os padrões relacionais vigentes nas famílias - descritos nas categorias precedentes -, pode-se pensar na repetição do padrão de vinculação primordial das participantes com seus pais. Esse padrão é atualizado e reatualizado permanentemente nas relações afetivas e conjugais.

A autoestima rebaixada foi outra característica apontada como típica de pessoas com TAs (Cassin \& Von Ransom, 2005; Peres \& Santos, 2006). Nesta pesquisa, essa questão parece ter sido agravada pela presença de relacionamentos conflituosos, nos quais as participantes se sentiam negligenciadas, abandonadas ou rejeitadas pelos homens em função do peso e da forma corporal. Acredita-se que o agravo à autoestima e os sentimentos negativos mencionados podem contribuir para intensificar os sintomas de TAs, funcionando tanto como gatilho quanto também como fatores mantenedores.

\section{Baixa densidade da rede social de amigos}

A densidade da rede social diz respeito à qualidade das conexões estabelecidas entre os membros da rede, de forma independente do controle da pessoa informante (Sluzki, 1997). A importância dessa categoria de análise é pautada no fato de que a articulação entre os membros da rede favorece o acionamento das fontes de apoio social no enfrentamento do quadro da pessoa acometida por uma doença grave (Moré, 2005).

A literatura ratifica o importante papel dos relacionamentos íntimos de amizade no ciclo vital de jovens adultos. Constatou-se baixa densidade da rede social de amigos, o que favorece o isolamento ou é consequência deste. Com efeito, o isolamento social foi um dado convergente nas narrativas de sete participantes - Bárbara, Carolina, Sofia, Juliana, Amanda, Sissi e Ana. Resulta do incômodo vivenciado ao se relacionar com outras pessoas e a consequente resposta de evitação frente à desconfiança nas relações interpessoais. As condutas de evitação podem ser vislumbradas no fato de as participantes não criarem novos vínculos e evitarem frequentar lugares públicos.

Sissi relatou que evitava sair de casa por ter certeza de que iria vomitar em qualquer lugar público onde estivesse. Bárbara, por sua vez, referiu que não gostava de "estar no meio de muita gente", pois acreditava que as pessoas reparavam muito nela e que mantinham os olhos fixos em sua aparência. Admitia ter "mania de perseguição". Carolina apresentou um relato semelhante ao de Bárbara: "não gosto de viver no meio das pessoas, num monte de pessoas aglomeradas, prefiro ficar só".

Juliana relatou que havia desenvolvido "um modo de agir, um modo de viver, um modo de ser, que mantinha as pessoas sempre longe" dela, pois "tinha a autoestima muito baixa e não se gostava". Sofia afirmou que o isolamento sempre foi uma constante em sua vida, mas sua dificuldade de socialização foi intensificada com o aparecimento do TA.

[...] mas antes eu já era mais fechada, mais isolada... Sempre fui de ficar mais em um canto, não consigo me lembrar de uma época onde eu fui de ficar em uma turminha assim, eu não lembro. Eu sempre fui de ficar mais isolada, mais no meu canto, e isso também com a comida, assim. (Juliana)

Apesar de se isolarem do meio social, Sissi e Bárbara relataram o desejo de permanecerem integradas à rede. Ambas mencionaram que se sentem muito sozinhas e desprotegidas, admitindo que apreciariam desfrutar de maior proximidade com os amigos. Nota-se mais uma vez a ambivalência, pois ao mesmo tempo em que desejam estar inseridas na rede, esforçam-se para se manter fora dela. Nesse sentido, considera-se que a baixa autoestima e o isolamento comprometem as possibilidades de as participantes se relacionarem afetivamente com o sexo oposto, uma vez que suas redes sociais são bastante restritas, o que dificulta ou impede o acesso a novos contatos.

\begin{abstract}
Ah, sabe assim? Pô, é chato, sabe? Tá todo mundo junto, assim... Você quer ficar sozinha? Você não quer ficar sozinha, sabe... Dai, às vezes, eu até dava umas indiretas, assim... Mas eu não tenho coragem de chegar e falar. [...] Porque eu acho que, quando você quer a companhia da pessoa, você chama, não precisa ficar a pessoa se oferecendo. (Bárbara)
\end{abstract}

Oito participantes - Bárbara, Carolina, Marina, Amanda, Sissi, Ana, Estrelinha e Grazieli - mostraram estabelecer uma distinção entre as categorias "colegas" e "amigos", ao definirem como colegas aquelas pessoas com quem elas convivem no cotidiano, mas com as quais não mantêm uma relação de intimidade, ou seja, não compartilham eventos e sentimentos significativos de suas vidas. Dessa forma, consideraram que tinham muitos colegas, porém poucos amigos.

Acredita-se que esses achados mantêm estreita relação com a dificuldade que mulheres com TAs enfrentam para estabelecer vínculos concretos e duradouros, uma vez que se apresentam muito retraídas no convívio social e adotam frequentemente condutas de evitação (Cassin \& Von Ranson, 2005; Nilsson et al., 2008; Peres \& Santos, 2006). A presença de membros nas redes sociais com quem as participantes 
mantêm apenas uma relação superficial (Sluzki, 1997), sem se permitirem estabelecer um vínculo de intimidade, pode comprometer o potencial de apoio da rede, pois as mulheres não contam com a ajuda desses membros em situações de necessidade física ou emocional.

\section{Atividades de lazer/convivência e empobrecimento da vida social}

Essa categoria está relacionada à realização de atividades de lazer na companhia de amigos, familiares, namorados e/ ou outras pessoas com quem as participantes convivem nas redes sociais. O lazer envolve um conjunto de atividades que o indivíduo realiza com prazer visando à satisfação pessoal, o descanso e o entretenimento (Pratta \& Santos, 2007). Tais atividades podem englobar: idas a restaurantes, bares, festas, cinema e eventos sociais em geral, assim como a prática de esportes e a realização, compartilhada ou não, de atividades prazerosas, como hobbies e diversão.

A maior parte das participantes - Bárbara, Sofia, Maria, Fernanda, Marina, Estrelinha, Ana e Grazieli - dedicavase a poucas atividades de lazer. As atividades eram predominantemente solitárias e desenvolvidas dentro de casa: artesanato (Maria), ler e ouvir música (Fernanda e Sofia), navegar na internet (Sofia). Essa condição fica evidente no relato de Sofia: "Meu lazer é dentro de casa", o que reafirma $\mathrm{o}$ isolamento social analisado na categoria anterior.

Bárbara e Grazieli relataram frequentar shopping center e cinema com seus respectivos namorados. No entanto, Bárbara considera muito difícil se engajar em atividades fora de casa, pois sempre há algum tipo de comida envolvida nas interações sociais. Dessa forma, a participante relata que o namorado tinha que se esforçar muito para convencêla a sair. Apenas três participantes - Amanda, Estrelinha e Juliana - referiram que realizavam atividades de lazer com certa frequência. Essas atividades envolviam a manutenção do convívio social, como: ir a festas, bares, reuniões na casa de amigos, entre outras.

Em contrapartida, Carolina e Sissi relataram que não mantinham atividades de lazer. Antes da instalação do TA, Sissi costumava frequentar academia, fazia aulas de dança do ventre, corria e "saía muito em balada". No entanto, atualmente, sente-se indisposta e prefere ficar sozinha em casa. Carolina, por sua vez, relatou que costumava sair com seu primeiro marido para restaurantes e festas, mas que "parou com essas atividades há muitos anos".

Duas participantes - Juliana e Estrelinha - apontaram que a possibilidade de usufruírem de atividades de lazer e convivência parece ser constantemente prejudicada devido aos conflitos com os respectivos namorados. Relataram que, quando saíam com os namorados, acabavam brigando por motivos de ciúme, de modo que preferiam não sair de casa. As atividades de lazer acabavam se restringindo às realizadas com as poucas amigas.

Sluzki (1997) aponta que as relações mantidas com as pessoas do meio garantem o desenvolvimento da identidade e fortalecem os sentimentos de segurança e bem-estar do indivíduo. Foi possível notar que as atividades de lazer referidas pelas participantes são bastante escassas e solitárias, o que é consistente com uma vida social empobrecida. Acredita-se que esse esgarçamento da vida social pode resultar em sentimentos de não pertencimento ao ambiente em que vivem, acentuando a incapacidade de se sintonizarem socialmente.

\section{Considerações Finais}

O objetivo desta pesquisa foi investigar a rede social de mulheres com TAs, com ênfase em suas relações afetivas. Constatou-se a proeminência da rede familiar, isto é, constituída por pessoas com as quais as participantes mantinham vínculos naturalizados por laços consanguíneos antes da instalação do TA. A análise de dados indicou padrões convergentes de funcionamento na vida familiar. Esses padrões são marcados por tensões decorrentes de pontos de dissenso e exigências, e parecem estar relacionados às modalidades de vínculos afetivos e conjugais que as participantes estabeleceram ao longo da vida, que também são permeados por insatisfações acentuadas pela falta de resolução adequada dos conflitos.

Também foi encontrada escassez de relacionamentos significativos com amigos, colegas de trabalho e indivíduos provenientes de outras redes sociais. A precariedade das relações interpessoais contribui para dissuadir novas aproximações no convívio diário, restringindo as possibilidades de trocas e enriquecimento pessoal. Esses dados sugerem dificuldades no estabelecimento de vínculos de um modo geral e, em particular, na manutenção de relacionamentos afetivo-familiares e conjugais estáveis e duradouros.

A configuração da rede de apoio social tanto pode afetar como ser afetada pelo quadro psicopatológico. De um modo geral, pode-se afirmar que a dinâmica das relações sociais e familiares das mulheres com TAs investigadas no presente estudo é marcada por fraturas, que levam ao isolamento e permanente insatisfação, intensificando os efeitos segregadores do estigma relacionado ao transtorno.

As participantes que tinham a experiência de ter mantido anteriormente relacionamentos afetivos e/ou conjugais relataram inúmeras situações conflituosas, permeadas por divergências, cobranças e discussões frequentes com seus parceiros. Os relatos acerca desses relacionamentos eram bastante similares às descrições que elas ofereceram a respeito da dinâmica familiar, ao caracterizarem as relações vivenciadas na família de origem como turbulentas ou marcadas pela indiferença e distanciamento afetivo.

Os dados sugerem possível transmissão de padrões transgeracionais de relacionamentos afetivos. As relações que as participantes mantêm com namorados e/ou cônjuges no presente são marcadas pela repetição de padrões de vínculos familiares disfuncionais que transitam, sem possibilidade de elaboração psíquica, entre as gerações.

Nesse sentido, deve-se sensibilizar o profissional de saúde para a necessidade de ampliar o conhecimento sobre a qualidade dos vínculos significativos que as mulheres com TAs estabelecem com os membros de suas redes sociais. Recomenda-se que os profissionais da área se esforcem para envolver os membros dessas redes na assistência, buscando 
explorar o potencial de apoio das redes sociais, de modo a melhorar os padrões relacionais.

A inclusão desses membros pode contribuir para o fortalecimento das redes de apoio social das pessoas com TAs. Tal fortalecimento das redes pode resultar em melhor qualidade de vida, uma vez que já está bem documentado na literatura que a qualidade de vida é intimamente relacionada à qualidade das relações sociais que a pessoa é capaz de estabelecer em seu convívio cotidiano.

\section{Referências}

Abreu, N., \& Filho, R. C. (2004). Anorexia nervosa e bulimia nervosa: Abordagem cognitivo-construtivista de psicoterapia. Revista de Psiquiatria Clínica, 31(4), 177-183.

Andrade, L. H. S. G., Viana, M. C., \& Silveira, C. M. (2006). Epidemiologia dos transtornos psiquiátricos na mulher. Revista de Psiquiatria Clínica, 33(2), 43-54.

Associação Americana de Psiquiatria (2002). DSM-IV-TRTM - Manual diagnóstico e estatístico de transtornos mentais: Texto revisado (C. O. Dornelles, Trad., $4^{\mathrm{a}}$ ed. revisada). Porto Alegre: Artmed.

Berge, J. M., Loth, K., Hanson, C., Croll-Lampert, J., \& NeumarkSztainer, D. (2012). Family life cycle transitions and the onset of eating disorders: A retrospective grounded theory approach. Journal of Clinical Nursing, 21(9-10), 1355-1363.

Bogdan, R. C., \& Biklen, S. K. (1994). Investigação qualitativa em educação: uma introdução à teoria e aos métodos (M. J. Alvarez, S. B. Santos, T. M. Batista, Trads.). Porto, Portugal: Ciência da Educação.

Borges, N. J. B. G., Sicchieri, J. M. F., Ribeiro, R. P. P., Marchini, J. S., \& Santos, J. E. (2006), Transtornos alimentares: Quadro clínico. Medicina (Ribeirão Preto), 39(3), 340-348.

Brusset, B. (2003). Introdução geral. In B. Brusset, C. Couvreur, \& A. Fine (Eds.), A bulimia (pp. 7-13). São Paulo: Escuta.

Bryant-Waugh, R., \& Lask, B. (1995). Eating disorders: An overview. Journal of Family Therapy, 17(1), 13-30.

Campana, A. N. N. B., Tavares, M. C. G. C. F., \& Garcia Júnior, C. (2012). Body dissatisfaction and concern, body checking and avoidance behavior in people with eating disorders. Paidéia (Ribeirão Preto), 22(53), 375-381.

Cassin, S. E., \& Von Ranson, K. M. (2005). Personality and eating disorders: A decade in review. Clinical Psychology Review, 25(7), 895-916.

Claudino, A. M., \& Borges, M. B. F. (2002). Critérios diagnósticos para os transtornos alimentares: Conceitos em evolução. Revista Brasileira de Psiquiatria, 24(3), 7-12.

Cooper, M. J., Deepak, K., Grocutt, E., \& Bailey, E. (2007). The experience of 'feeling fat' in women with anorexia nervosa, dieting and non-dieting women: An exploratory study. European Eating Disorders Review, 15(5), 366-372.

Dallos, R., \& Denford, S. (2008). A qualitative exploration of relationship and attachment themes in families with an eating disorder. Clinical Child Psychology and Psychiatry, 13(2), 305-322.

Dimitropoulos, G., Carter, J., Schachter, R., \& Woodside, D. B. (2008).Predictors of family functioning in carers of individuals with anorexia nervosa. International Journal of Eating Disorders, 41(8), 739-747.
Filho, N. G. V., \& Nóbrega, S.M. (2004). A atenção psicossocial em saúde mental: contribuição teórica para o trabalho terapêutico em rede social. Estudos de Psicologia, 9(2), 373-379.

Kluck, A. S. (2008). Family factors in the development of disordered eating: Integrating dynamic and behavioral explanations. Eating Behaviors, 9(4), 471-483.

Lane, R. C. (2002). Anorexia, masochism, self-mutilation, and autoerotism: The spider mother. Psychoanalitic Review, 89(1), 101-123.

Leonidas, C. (2012). Redes sociais e apoio social no contexto dos transtornos alimentares. (Unpublished master's thesis). Universidade de São Paulo, Ribeirão Preto.

Leonidas, C., \& Santos, M. A. (2012). Imagem corporal e hábitos alimentares na Anorexia Nervosa: Uma revisão integrativa da literatura. Psicologia: Reflexão e Crítica, 25(3), 550-558.

Leonidas, C., Crepaldi, M. A., \& Santos, M. A. (2013). Bulimia nervosa: uma articulação entre aspectos emocionais e rede de apoio social. Psicologia: Teoria e Prática, 15(2), 62-75.

Limbert, C. (2010). Perceptions of social support and eating disorder characteristics. Health Care for Women International, 31(2), 170-187.

Marcos, Y. Q., \& Cantero, M. C. T. (2009). Assessment of social support dimensions in patients with eating disorders. The Spanish Journal of Psychology, 12(1), 226-235.

McGoldrick, M., Gerson, R., \& Petry, S. (2008). Genograms: assessment and intervention ( $\left.3^{\mathrm{a}} \mathrm{ed}\right)$. Nova York: W. W. Norton Co Inc.

McNamara, K., \& Loveman, C. (1990). Differences in family functioning among bulimics, repeat dieters, and nondieters. Journal of Clinical Psychology, 46(3), 518-523.

Moré, C. L. O. O. (2005). As redes pessoais significativas como instrumento de intervenção psicológica no contexto comunitário. Paidéia (Ribeirão Preto), 15(31), 287-297.

Morgan, C. M., Vecchiatti, I. R., \& Negrão, A. B. (2002). Etiologia dos transtornos alimentares: aspectos biológicos, psicológicos e socioculturais. Revista Brasileira de Psiquiatria, 24(3), 18-23.

Nilsson, K., Sundbom, E., \& Häglöf, B. (2008). A longitudinal study of perfectionism in adolescent onset anorexia nervosa, restricting type. European Eating Disorders Review, 16(5), 386-394.

Oliveira, E. A., \& Santos, M. A. (2006). Perfil psicológico de pacientes com anorexia e bulimia nervosas: A ótica do psicodiagnóstico. Medicina (Ribeirão Preto), 39(3), 353-360.

Oliveira, L. L., \& Hutz, C. S. (2008). Padrões de interação em famílias de adolescentes com anorexia nervosa restritiva e bulímica: semelhanças e diferenças. Estudos e Pesquisas em Psicologia, 8(3), 712-746.

Orlandi, R. (2011). Participação da rede social significativa de mulheres que vivem e convivem com o HIV no enfrentamento da soropositividade. (Unpublished doctoral dissertation). Universidade Federal de Santa Catarina, Florianópolis.

Peres, R. S., \& Santos, M. A. (2006). Contribuições do Desenho da Figura Humana para a avaliação da imagem corporal na anorexia nervosa. Medicina (Ribeirão Preto), 39(3), 361-370.

Pratta, E. M. M., \& Santos, M. A. (2007). Lazer e uso de substâncias psicoativas na adolescência: possíveis relações. Psicologia: Teoria e Pesquisa, 23(1), 43-52. 
Prisco, A. N. C., Araújo, T. M., Almeida, M. M. G., \& Santos, K. O. B. (2013). Prevalência de transtornos alimentares em trabalhadores urbanos de município do Nordeste do Brasil. Ciência \& Saúde Coletiva, 18(4), 1109-1118.

Ramos, T. M. B., \& Pedrão, L. J. (2013). User embracement and bonding at a care service for patients with eating disorders. Paidéia (Ribeirão Preto), 23(54), 113-120.

Resende, M. C., Bones, V. M, Souza, I. S., \& Guimarães, N. K. (2006). Rede de relações sociais e satisfação com a vida de adultos e idosos. Psicologia para a América Latina, 5. Retrieved from http://pepsic.homolog.bvsalud. org/scielo. php?script $=$ sci_arttext\&pid $=$ S187050X2006000100015\&ln $\mathrm{g}=\mathrm{pt \& nrm}=$ iso.

Rosa, B. P., \& Santos, M. A. (2011). Comorbidade entre bulimia nervosa e transtorno de personalidade borderline: Implicações para o tratamento. Revisa Latinoamericana de Psicopatologia Fundamental, 14(2), 268-282.

Scorsolini-Comin, F., Souza, L. V., \& Santos, M. A. (2010). A construção de si em um grupo de apoio para pessoas com transtornos alimentares. Estudos em Psicologia (Campinas), 27(4), 467-478.
Souza, L. V., \& Santos, M. A. (2009). A construção social de um grupo multifamiliar no tratamento dos transtornos alimentares. Psicologia: Reflexão e Crítica, 22(3), 317-26.

Souza, L. V., \& Santos, M. A. (2010). A participação da família no tratamento dos transtornos alimentares. Psicologia em Estudo (Maringá), 15(2), 285-294.

Soenens, B., Vamsteenkiste, M., Vandereycken, W., Luyten, P., Sierens, E., \& Gloossens, L. (2008). Perceived parental psychological control and eating-disordered symptoms: Maladaptative perfectionism as a possible intervening variable. The Journal of Nervous and Mental Disease, 196(2), 144-152.

Sluzki, C. E. (1997). A rede social na prática sistêmica: Alternativas terapêuticas (C. Berliner, Trad.). São Paulo: Casa do Psicólogo.

Valdanha, E. D, Scorsolini-Comin, F., \& Santos, M. A. (2013). Anorexia nervosa e transmissão psíquica transgeracional. Revista Latinoamericana de Psicopatologia Fundamental, 16(1), 71-78.

Wendt, N. C., \& Crepaldi, M. A. (2008). A utilização do genograma como instrumento de coleta de dados na pesquisa qualitativa. Psicologia: Reflexão e Crítica, 21(2), 302-310.

Wright, L., \& Leahy, M. (2002). Enfermeiras e família: um guia para avaliação e intervenção na família. $3^{\mathrm{a}}$ ed. São Paulo: Roca. 